\title{
MODELAGEM 2-D DE DADOS GRAVIMÉTRICOS E AEROMAGNÉTICOS DE CUBA CENTRO-ORIENTAL
}

\author{
RIGOBERTO LÁZARO PRIETO CAINZOS, ELISABETE MARIAPASCHOLATI \& \\ CARLOS ROBERTO DE SOUZA FILHO
}

\begin{abstract}
TWO DIMENSIONAL MODELING OF GRAVIMETRIC AND AEROMAGNETIC DATA OF CENTRAL EASTERN $C U B A$ This paper shows the results of a 2-D geologic-geophysical modeling of central-eastern Cuba. This was achieved through SW-NE-trending sections using gravimetric and magnetic data. The study area comprises broad sectors of key geologic units recognized in Cuba, such as the Cretaceous volcanic arc (CVA), the Mesozoic ophiolites, the margin of the Bahamas continental platform (Upper Jurassic-Upper Cretaceous) and the Cenozoic cover. The region's unique geologic characteristics, including a variety of rocks and structures, make it an attractive site to evaluate geophysical methods and their usefulness in geologic mapping. The 2D modeling (interactive, direct method) involved the conception of an initial model that was calculated on the basis of the geologicgeophysical behavior of sources responsible for the geophysical anomalies, and subsequent adjustment of gravimetric and magnetic models. This yielded a comprehensible distinction between units of the volcanic arc and ophiolites, and also the distinction among these oceanic units and the continental unit (Bahamas platform).
\end{abstract}

Keywords: airborne geophysics, geological modeling, ophiolites, volcanic arc, continental platform, Cuba

\begin{abstract}
Resumo O presente artigo apresenta os resultados da modelagem geológico-geofísica 2-D da região de Cuba Centro-Oriental, através de perfis de direção SW-NE, utilizando dados gravimétricos e magnetométricos. Essa região compreende setores das principais unidades geológicas documentadas no arquipélago cubano, as quais incluem o arco de ilha Cretácico (AVC), os ofiolitos Mesozóicos, a margem continental da plataforma das Bahamas (Jurássico Superior-Cretáceo Superior) e a cobertura sedimentar Cenozóica. Cuba Centro-Oriental é marcada por uma grande diversidade de rochas e estruturas, o que a torna atrativa para a utilização e avaliação de modelos geofísicos aplicados ao mapeamento geológico. A modelagem 2-D (método direto interativo) compreendeu a criação de um modelo inicial, calculado com base no comportamento geológico-geofísico das fontes responsáveis pelas anomalias geofísicas, e a comparação dos parâmetros da anomalia calculada com aqueles da anomalia observada, para posterior ajuste. O ajuste dos modelos gravimétrico e magnético permitiu discriminar as unidades oceânicas (seqüências ofiolíticas - arco vulcânico) da unidade continental (Plataforma das Bahamas).
\end{abstract}

Palavras-chave: aerogeofísica, modelagem geológica, ofiolitos, arco vulcânico, plataforma continental, Cuba

INTRODUÇÃO A maior expressão geológico-estrutural em Cuba Centro-Oriental, no contexto da evolução do Caribe, é o Arco Vulcânico Cretácico (AVC). Diversos modelos sobre a evolução tectônica desse arco têm sido propostos, entre os quais se destacam aqueles de Iturralde-Vinent et al. (2000), Meschede \& Frisch (1998) e Stanek et al. (2000). Contudo, em que pese os esforços realizados em anos recentes, pouco ainda se conhece sobre os processos de reativação magmática do AVC, o arranjo e a composição das rochas pertencentes ao complexo ofiolítico e seu vínculo à zona de sutura. Além disso, há uma controvérsia histórica sobre a polaridade das estruturas vinculadas a subducçãocolisão das placas oceânicas do Caribe e continental, da Plataforma das Bahamas (Iturralde-Vinent et al. 2000, Stanek et al. 2000, Kerr 1999).

Este trabalho pretende contribuir com a modelagem 2-D de dados gravimétricos e aeromagnéticos da região de Cuba CentroOriental, a partir de três perfis de direção SW-NE (Fig. 1), com o objetivo mais amplo de dar suporte à interpretação da geologia regional e auxiliar na discussão e solução de questões de fronteira sobre a geologia do Caribe.

GEOLOGIA REGIONAL A geologia de Cuba é considerada como uma das mais complexas da região do Caribe (Iturralde-Vinent et al. 2000). A partir da década de 60, o arquipélago passou a ser estudado sistematicamente, através de levantamentos geológicos básicos conduzidos por geólogos cubanos e do antigo bloco socialista (Furrazola et al. 1964, Khudoley \& Meyerhoff 1971, Shein 1974, Puscharowski et al. 1989). Recentemente, a geologia do território cubano tem sido tratada num contexto mais amplo, principalmente quanto ao seu papel na origem e evolução do Caribe (Ross \& Scotese 1988, Pindell et al. 1988, Iturralde-Vinent 1997, Meschede \& Frisch 1998).

$\mathrm{O}$ arcabouço geológico de Cuba, segundo o modelo geológico de Iturralde-Vinent (1997), apresenta dois níveis estruturais principais reconhecidos no arquipélago: o substrato dobrado e o neoautóctone (Fig. 1).

O substrato dobrado (Campaniano Médio até Eoceno Superior) é formado por diferentes unidades, variavelmente alóctones, de 
natureza continental e oceânica. Os terrenos continentais são representados por núcleos de alto grau metamórfico (Bloco "Yucatan") e pela Plataforma das Bahamas. Os terrenos de natureza oceânica incluem os ofiolitos setentrionais e os arcos insulares, sendo o maior, do Cretáceo e o menor, do Paleógeno.

O neo-autóctone (Eoceno Superior-Quaternário) compreende rochas e estruturas geradas posteriormente à consolidação do substrato dobrado (Eoceno superior), quando predominaram movimentos verticais que levaram à formação de blocos com espessuras de sedimentos de centenas a milhares de metros.

CONTEXTOGEOLÓGICODECUBACENTRO-ORIENTAL A área de estudo, Cuba Centro-Oriental, apresenta os dois níveis estruturais expostos (Iturralde-Vinent 1997). O substrato dobrado é constituído por diversas unidades alóctones, de natureza continental e oceânica, cuja origem e evolução está relacionada a processos orogenéticos ocorridos fora dos limites atuais do território cubano. À unidade de natureza continental, pertencem os terrenos da Plataforma das Bahamas (Zona Remédios) e as Seqüências do Protocaribe. As unidades de natureza oceânica incluem partes da crosta antiga do Caribe (ofiolitos do Cinturão Setentrional) e o Arco Vulcânico Cretácico (Figuras 2 e 3). O neo-autóctone é representado por rochas e estruturas desenvolvidas, principalmente, na posição atual de Cuba.

SUBSTRATO DOBRADODE NATUEREZA CONTINENTAL A Plataforma das Bahamas (PB) situa-se ao norte de Cuba e é constituída por zonas dobradas com estratigrafia própria, denominadas Canal Velho das Bahamas, Calho Coco e Remédios (esta última, presente na área de estudo) (Fig. 3).

A Zona Remédios situa-se na periferia meridional da Plataforma das Bahamas e é composta por seqüências de até $2000 \mathrm{~m}$ de calcários e dolomitos (Figuras 2 e 3), formados em águas pouco profundas (Díaz et al. 1997). Essas rochas estão intensamente deformadas por falhas de cavalgamento e por dobras.

As Seqüências do Protocaribe (SP) encontram-se numa faixa dobrada entre a Plataforma das Bahamas (Zona Remédios) e os terrenos alóctones de natureza oceânica (ofiolitos, arco vulcânico). Essa faixa, hoje conhecida como zonas Camajuaní e Placetas (Furrazola et al. 1964), foi originada pela compressão dos sedimentos e da crosta protocaribenha, como conseqüência da colisão do alóctono oceânico contra a margem continental das
Bahamas. As SP compreendem calcários estratificados, dolomitos e basaltos na base, com espessuras de milhares de metros (Figuras 2 e 3 ).

SUBSTRATODOBRADODENATUREZAOCEÂNICA AAssociação Ofiolítica do Cinturão Setentrional (AO) ou Ofiolito Camaguey (Figuras 2 e 3), forma uma faixa com geometria em arco, de aproximadamente $1000 \mathrm{~km}^{2}$. Dados oriundos de testemunhos de sondagem e gravimetria indicam que a espessura de rochas ultrabásicas que compõem esse ofiolito aumentam progressivamente de norte para sul, podendo chegar a pelo menos $5 \mathrm{~km}$ na região de Camaguey (Iturralde-Vinent et al. 2000).

$\mathrm{O}$ ofiolito Camaguey representa uma mélange tectônica e encontra-se em contato tectônico, a N-NE, com unidades da Plataforma das Bahamas (Seqüências do Protocaribe e Zona Remédios), por meio de um sistema de empurrões controlados por duas nappes principais. A norte, as falhas de empurrão apresentam mergulhos variáveis de $30^{\circ}$ a $45^{\circ}$ para $\mathrm{SW}$, os quais aumentam progressivamente na porção sul do ofiolito, onde se tornam subverticais a verticais (Fig. 2). A fase final de colocação do ofiolito sobre a Plataforma das Bahamas começou no Paleoceno e durou até o Eoceno Superior (Iturralde-Vinent et al. 2000).

As duas nappes principais compreendem uma sucessão ofiolítica similar, que contêm serpentinitos, peridotitos, gabros, basaltos e sedimentos pelágicos. A nappe inferior distingue-se da superior pelo conteúdo maior de sedimentos (e.g., unidade Sierra de Camaján, a norte de Camaguey).

Dentre os diversos ofiolitos descritos na região norte do Caribe, o ofiolito de Camaguey é o que possui a seqüência mais completa (Iturralde-Vinent et al. 2000), apresentando exposições das unidades peridotíticas (transicional e cumulática) e vulcano-sedimentar.

A unidade peridotítica é composta principalmente por harzburgitos, mas ainda contém websteritos, lherzolitos, raros dunitos e ocorrências isoladas de cromita. Localmente, diques gabróicos cortam as sequências de harzburgitos. A serpentinização que atingiu as rochas dessa unidade varia, em intensidade, de fraca (onde a textura magmática das rochas aparecem preservadas) a muito forte (quando as rochas apresentam-se completamente alteradas).

A unidade cumulática é a mais desenvolvida do ofiolito. Olivinagabros, noritos, troctolitos, assim como anortositos, formam grandes corpos com texturas de acamamento (layering) magmático.

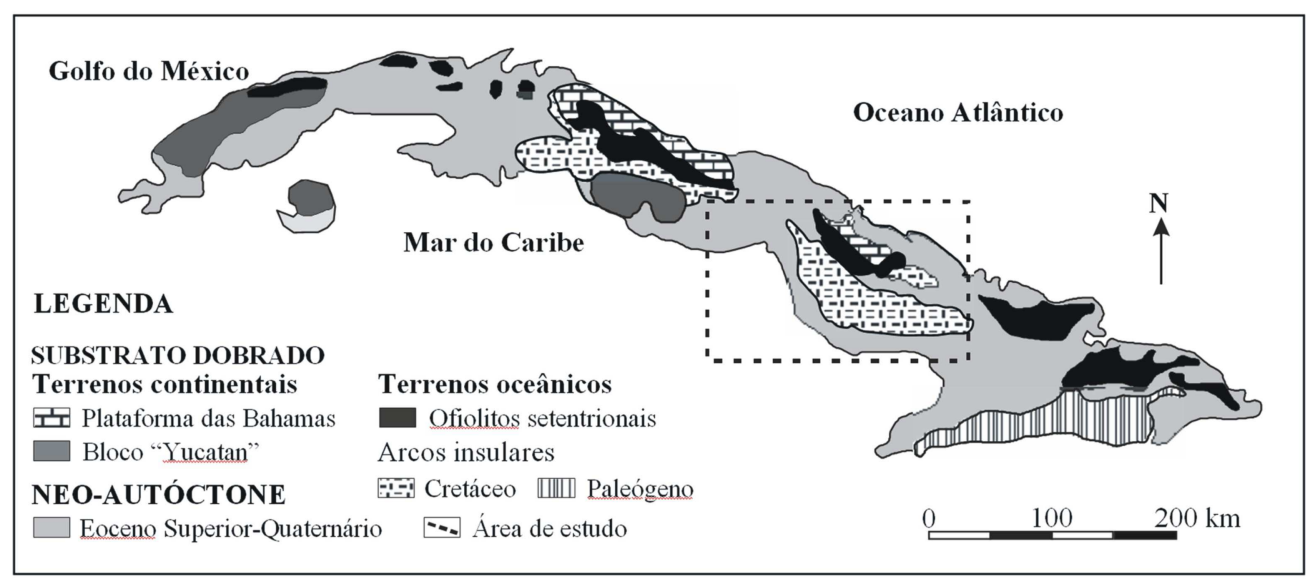

Figura 1 - Esboço geral da constituição geológica de Cuba (substrato dobrado e neo-autóctone) (modificado de Iturralde-Vinent 1997). 


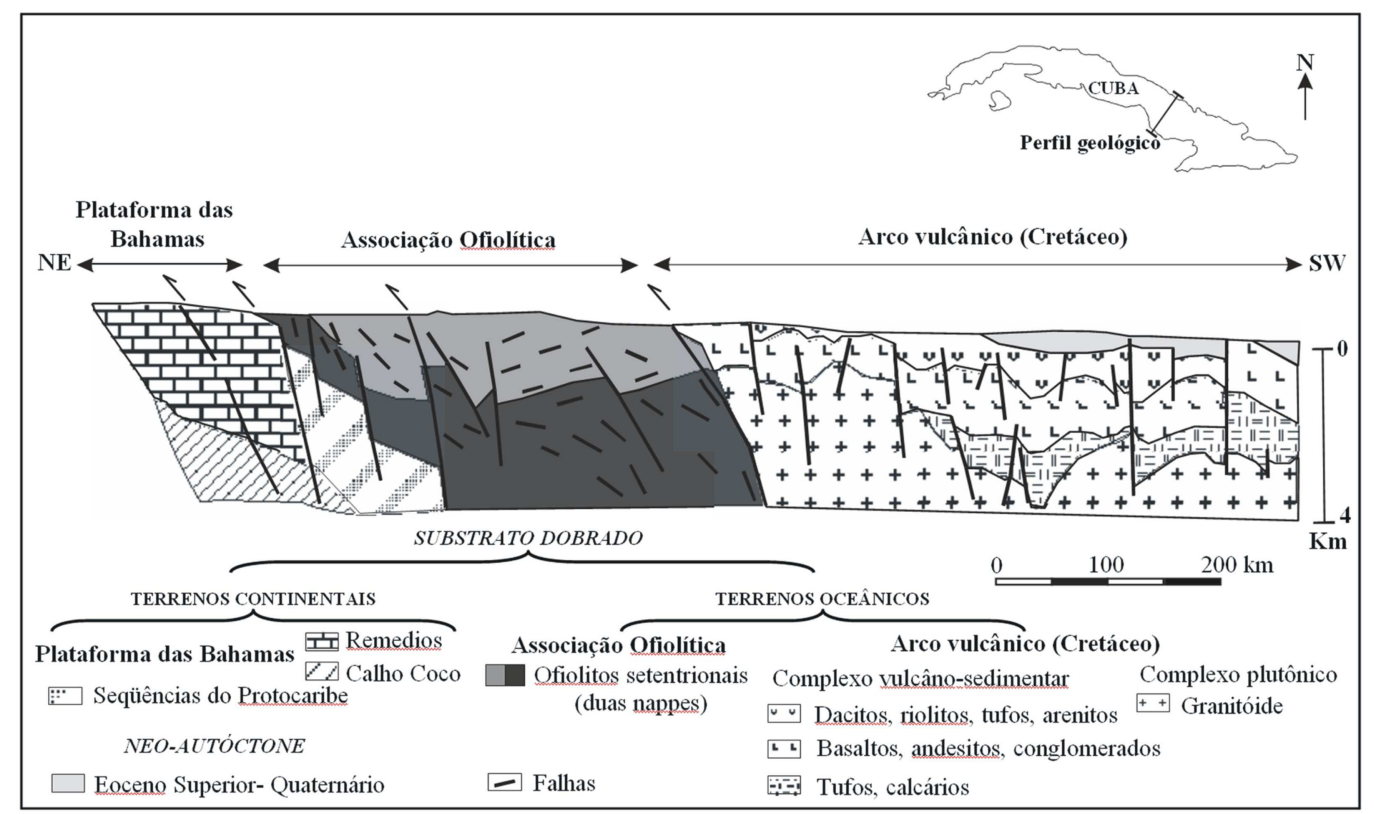

Figura 2 - Perfil geológico das principais estruturas do substrato dobrado em Cuba Centro-Oriental (região de Camaguey) (modificado de Iturralde-Vinent et al. 2000).

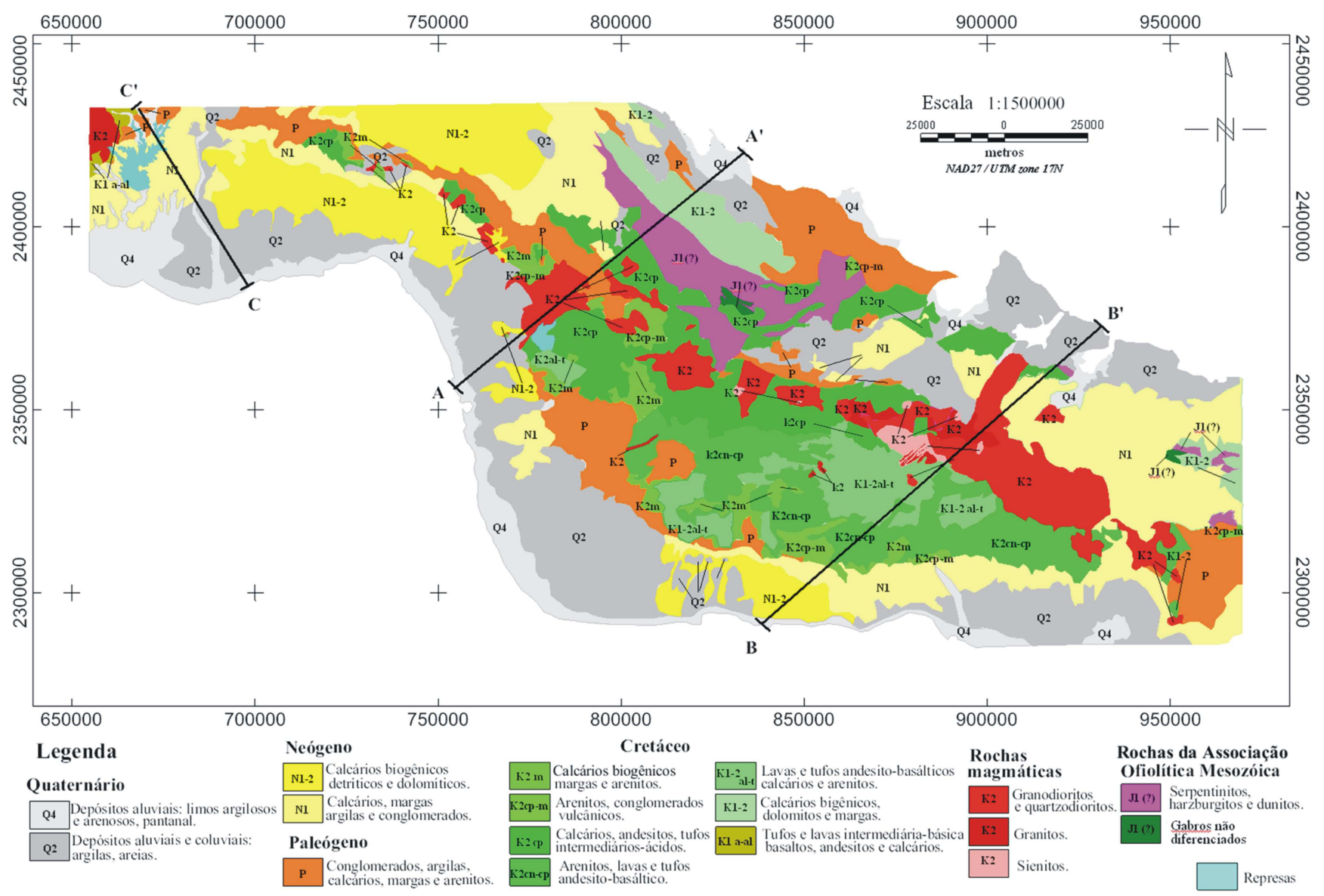

Figura 3 - Mapa litológico com a localização dos três perfis modelados, (modificado de Puscharowsky 1988). 
Na partes inferiores dessa unidade, rochas ultramáficas (lherzolitos, websteritos, harzburgitos e poucos dunitos) ocorrem entres os cumulados. Diques de gabros, plagioclasitos e plagiogranitos também foram documentados. Entre as unidades peridotítica e cumulática, existe uma zona de transição, que contém uma mistura de rochas ultramáficas e corpos irregulares, além de diques de gabro e plagioclasito.

Existem raras exposições de enxames de diques em Cuba Central. Em meio à associação ofiolítica próxima à localidade de $\mathrm{Mi}-$ mas, ocorre uma série de diques doleríticos, que foram interpretados, por Iturralde-Vinent et al. (2000), como sheeted dikes.

O complexo vulcano-sedimentar da sequência ofiolítica aparece sob a forma de lascas tectônicas em diversas localidades. Uma seção de basaltos, hyaloclastitos, cherts e siltitos (Formação Albaiza) aflora sob a forma de blocos isolados, de dimensões quilométricas, a sul da Serra de Camaján. Na porção NW da área, próximo a localidade de Esmeralda, fatias de calcários e de cherts hemipelágicos encontram-se inclusos em serpentinitos (Formação Mate Prieto). ANE da cidade de Camaguey, ocorre uma grande lasca tectônica contendo xistos verdes, quartzo-mica-xistos, calcários e xistos carbonosos.

Corpos de cromita podiforme são abundantes ao norte de Camaguey. Esses corpos, alguns dos quais compreendem depósitos de cromita de granulação média $\left(\sim 30 \% \mathrm{Cr}_{2} \mathrm{O}_{3}\right)$, estão relacionados a diferentes níveis estruturais no ofiolito e têm, como principais rochas hospedeiras, peridotitos e dunitos. A maior parte dos corpos de cromita situa-se na zona de transição entre os peridotitos e as rochas básicas ricas em feldspato, assim como nas porções inferiores da unidade cumulática. Em Meseta San Felipe, carapaças lateríticas derivadas da alteração supergênica de rochas ultramáficas mostram enriquecimento em $\mathrm{Ni}$.

Existem divergências sobre a origem dos ofiolitos de Camaguey. Alguns autores (Shein 1974, Ando et al. 1996) os relacionam ao complexo de subdução do arquipélago vulcânico cretácico; outros (Pushcharowsky et al. 1989, Iturralde-Vinent 1997) consideram os ofiolitos como relictos de uma bacia de retro-arco.

O Arco Vulcânico Cretácico (AVC) recobre tectonicamente os ofiolitos Camaguey (Figuras 2 e 3 ). O contato geralmente coincide com falhas de cavalgamento NW-SE (Rumo Cubano), apresentando zonas com foliação penetrativa, ou uma mistura complexa e caótica de blocos de rochas ofiolíticas e rochas derivadas do arco.

As rochas do arco podem ser caracterizadas como as de um antigo arquipélago de ilhas vulcânicas separadas por depressões e canais de água de diferente profundidade, onde coexistiram vulcões submarinos e insulares. $\mathrm{Na}$ área de estudo, são reconhecidos os complexos vulcano-sedimentares e plutônicos, com limites estratigráficos e tectônicos definidos (Figuras 2 e 3).

O Complexo Vulcano-sedimentar é formado, na base, por seqüências de vulcanismo básico com tendência alcalina, geradas em ambiente submarino. No topo, o complexo compreende rochas de composição intermediária-ácida (magmas riolíticos e dacíticos), desenvolvidas em ambiente submarino pouco fundo até subaéreo (Piñero et al. 1997). Na área de estudo, as rochas do Complexo Vulcano-sedimentar podem ser agrupadas em duas seqüências, que correspondem a duas bacias do antigo arquipélago vulcânico: a bacia de retro-arco e a bacia axial (Fig. 4).

A bacia de retro-arco é constituída por seqüências onde predominam rochas sedimentares com conteúdo de detritos vulcânicos relacionados às rochas da associação ofiolítica. Lavas e corpos sub-vulcânicos são pouco comuns nessa seqüência.

A bacia axial do arco engloba aparelhos vulcânicos com predo- mínio de lavas e corpos sub-vulcânicos e intercalações de tufos e rochas sedimentares. Associados a esses aparelhos, essencialmente na interface entre rochas vulcânicas e plutônicas, processos de metamorfismo de contato e alterações metassomáticas são observados.

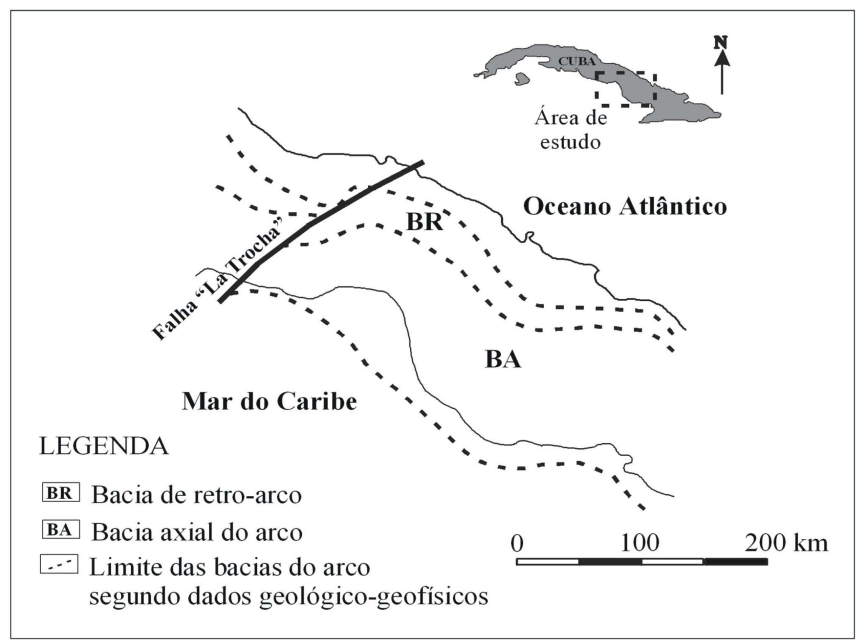

Figura 4 - Limite das bacias do arquipélago vulcânico (modificado de Iturralde-Vinent 1997).

As rochas plutônicas (Complexo Plutônico) contidas na área de estudo, de acordo com suas características petroquímicas, foram divididas em três séries: cálcio-alcalina normal, cálcio-alcalina sódica e alcalina (Marí et. al. 1997, Pérez \& Sukar 1997).

A série cálcio-alcalina normal possui a maior extensão em área. Seu conteúdo de $\mathrm{K}_{2} \mathrm{O}$ varia lateralmente, aumentando na região Camaguey-Las Tunas. É constituída por rochas do Complexo Tonalito-granodiorítico (quartzo-dioritos, monzodioritos e raros gabro-dioritos) (Fig. 3).

A série cálcio-alcalina sódica apresenta um desenvolvimento escasso na área de estudo, sendo constituída pelo Complexo Gabroplagiogranítico.

A série alcalina somente é reconhecida na região de Camaguey e é caracterizada por altas concentrações de $\mathrm{K}_{2} \mathrm{O}$, maiores que as de $\mathrm{Na}_{2} \mathrm{O}$. Essa série é representada pelo Complexo Gabro-sienítico, constituído principalmente por rochas sieníticas.

NEO-AUTÓCTONE O neo-autóctone é constituído por rochas e estruturas formadas posteriormente à consolidação do substrato dobrado (Eoceno Superior-recente), compreendendo extensas coberturas e grandes espessuras de rochas Cenozóicas (Figs. 2 e 3).

Segundo Iturralde-Vinent (1997), os movimentos verticais oscilatórios predominantes dessa etapa provocaram a formação de uma estrutura de blocos elevados a diferente altitude. Os blocos de altitude positiva apresentam pouca a nenhuma cobertura; no entanto, os blocos de altitude negativa apresentam até $3000 \mathrm{~m}$ de espessura de sedimentos. Nesses últimos, são reconhecidos três ciclos de transformação paleogeográfica, começando nas bacias com predomínio de sedimentos clásticos e terminando nas bacias com predomínio de calcários. 
SÍNTESE TECTONO-ESTRUTURAL O mapa geológico de Cuba na escala de 1:500 000 (Capote et al. 1992) apresenta a idade relativa dos principais tectono-lineamentos de Cuba e é, até hoje, utilizado como base para interpretações tectono-estruturais. Considerando a terminologia adotada nesse mapa, são expostos a seguir, os principais sistemas de lineamentos presentes na área de estudo (Fig. 5):

(i) Sistema "Cubano": de direção NW-SE, é representado geralmente por falhas normais relacionadas à evolução da faixa dobrada do arco. Essas falhas exerceram um forte controle no magmatismo do arco. A falha mais expressiva é a falha "Cubana Axial";

(ii) Sistema "Camaguey": de direção NE, é representado por falhas transtensivas profundas, bem expressas pelo relevo e pela geologia. Essas falhas separam blocos estruturais distintos e, possivelmente, foram reativadas de modo sucessivo durante a evolução da região. As falhas mais representativas desse sistema são "La Trocha" e "Camaguey";

(iii) Sistema "Banao": de direção N-S, compreende falhas com movimentação vertical, reversa e normal, relacionadas ao neo-autóctone.

EVOLUÇÃOTECTÔNICA REGIONAL Entre os modelos propostos nos últimos anos sobre a origem e evolução do Caribe, incluindo Cuba Centro-Oriental, destacam-se os de IturraldeVinnent et al. (1997, 2000). Segundo esses modelos, a região a sul da zona Remédios é caracterizada pela presença simultânea de rochas da associação ofiolítica e sedimentos do AVC (mélange), constituindo relictos de uma crosta de bacia de retro-arco. No entanto, Ando et al. (1996) e Pindell et al. (1988) defendem a idéia da relação dos ofiolitos ao complexo de subdução a norte, provavelmente de idade Alviana. A presença de rochas boniníticas encontradas em localidades a leste da área de estudo (pela primeira vez nas Antilhas), junto a rochas da associação ofiolítica (com datação de K-Ar entre 120-130 Ma ou mais antigas), sugere que ambos complexos sejam pré-Alvianos e que dois arcos de ilha coexistiram no estágio primário, na região (Kerr et al. 1999). O arco boninítico, ter-se-ia desenvolvido no Jurássico Superior-Cretáceo

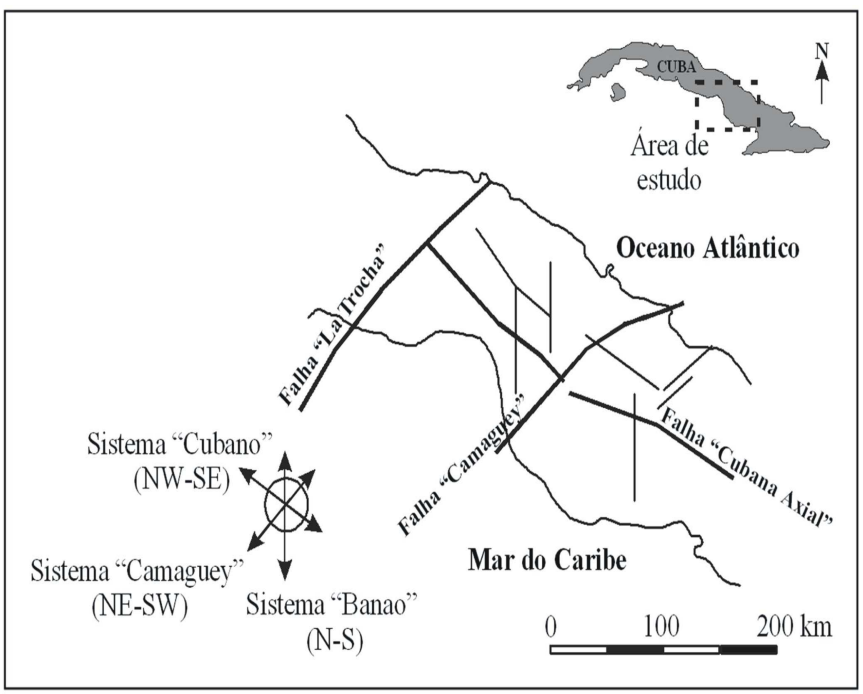

Figura 5 - Principais feições tectônicas em Cuba Centro-Oriental (modificado de Iturralde-Vinent 1997).
Inferior, a norte da atual mélange ofiolítica, e a sua gênese estaria ligada à presença de falhas transformantes relacionadas ao início da história evolutiva da zona de subdução. A inclinação da zona de subdução do arco primitivo boninítico em direção sul pressupõe a existência da bacia de retro-arco junto às rochas ofiolíticas. Por sua vez, essa bacia estaria geneticamente interligada à evolução do arco cretácico, localizado a sul (Fig. 6).

BASES PARAAMODELAGEM 2D Amodelagem 2-D naárea de estudo foi realizada utilizando-se o mapa geológico (Fig. 3); o mapa residual do campo gravimétrico calculado a partir do mapa de anomalia Bouguer com um filtro de continuação para baixo até 4.000 m (Fig. 7); o mapa residual do campo magnético calculado a partir do mapa do campo magnético anômalo com filtro de continuação para baixo até $2.000 \mathrm{~m}$ (Fig. 8); medidas de densidade e susceptibilidade magnética, obtidas em laboratório, sobre amostras coletadas na área de estudo (Tabela 1); e dados obtidos a partir de mapas petrofísicos regionais de Cuba (Vega et al. 1994), na escala de 1:1.000.000.

$\mathrm{Na}$ análise dos dados de petrodensidade foram considerados os processos que afetaram o grau de conservação das rochas, tais como intemperismo, tectônica, metamorfismo, entre outros. Os mapas residuais do campo gravimétrico (Fig. 7) e do campo magnético anômalo (Fig. 8), foram obtidos a partir da interpolação (método de Kriggagem Linear) da base de dados em formato ASCII $(\mathrm{x}, \mathrm{y}, \mathrm{z})$, respectivamente, do levantamento gravimétrico na escala 1:250.000 e do levantamento aeromagnético na escala de 1:50.000.

$\mathrm{O}$ processo de modelagem dos dados gravimétricos e aeromagnéticos foi realizado em uma série de etapas, descritas a seguir:

1- seleção de um modelo geológico para a área de estudo. $\mathrm{O}$ modelo conceitual de Iturralde-Vinent (1997) e Iturralde-Vinent et al. (2000) foi proposto com base em trabalhos de campo sistemáti-

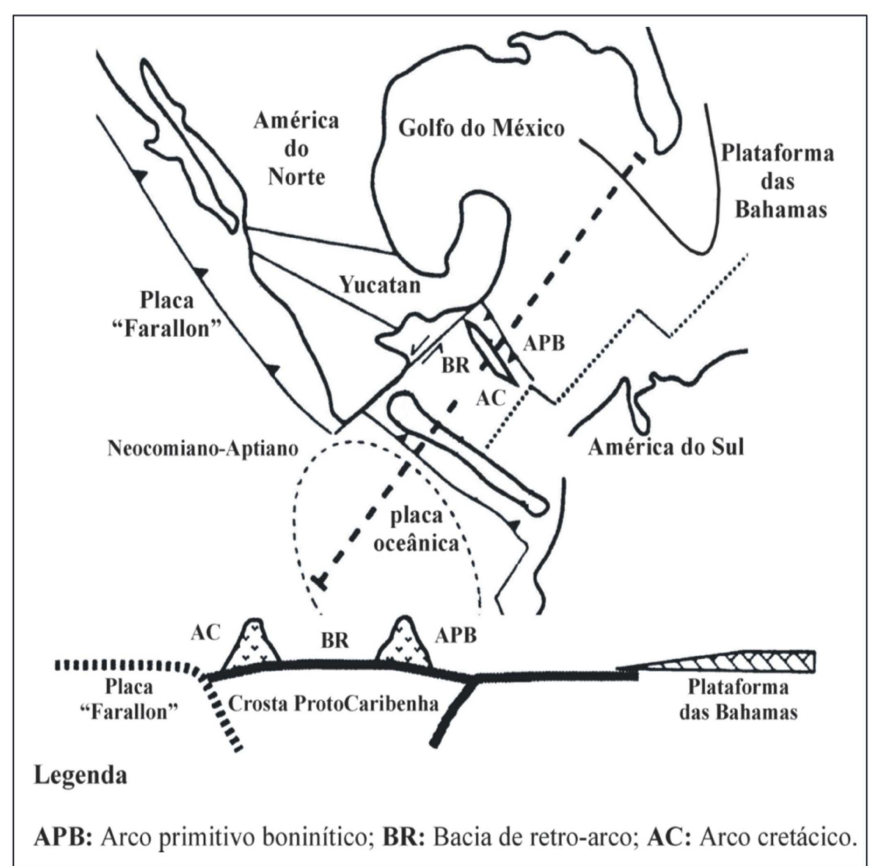

Figura 6 - Evolução do cinturão dobrado no contexto do Caribe no Neocomiano-Aptiano (modificado de Kerr et al. 1999). 
Modelagem 2-D de Dados Gravimétricos e Aeromagnéticos de Cuba Centro-Oriental

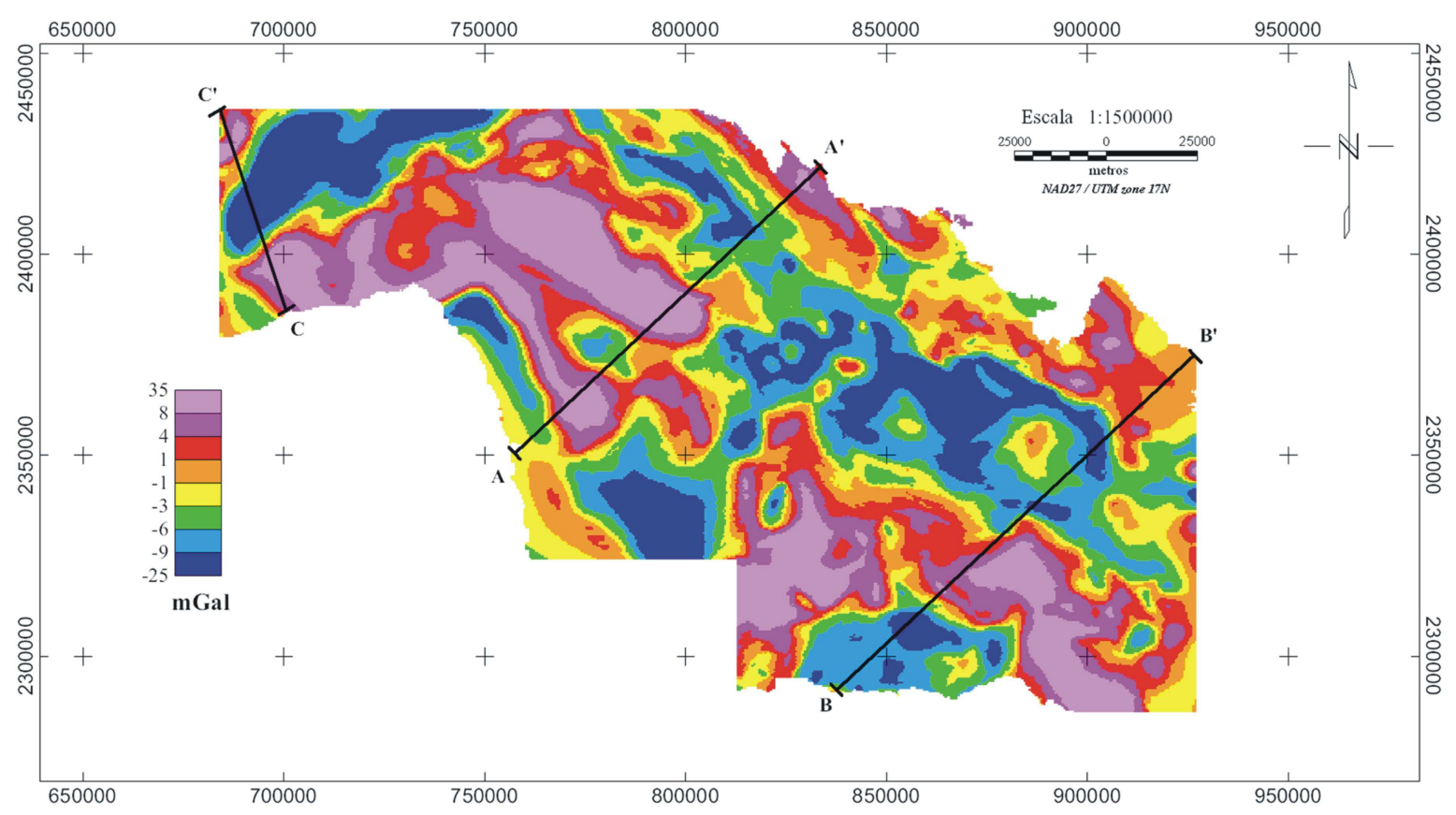

Figura 7 - Mapa residual do campo gravimétrico até $4.000 \mathrm{~m}$, com perfis de modelagem.

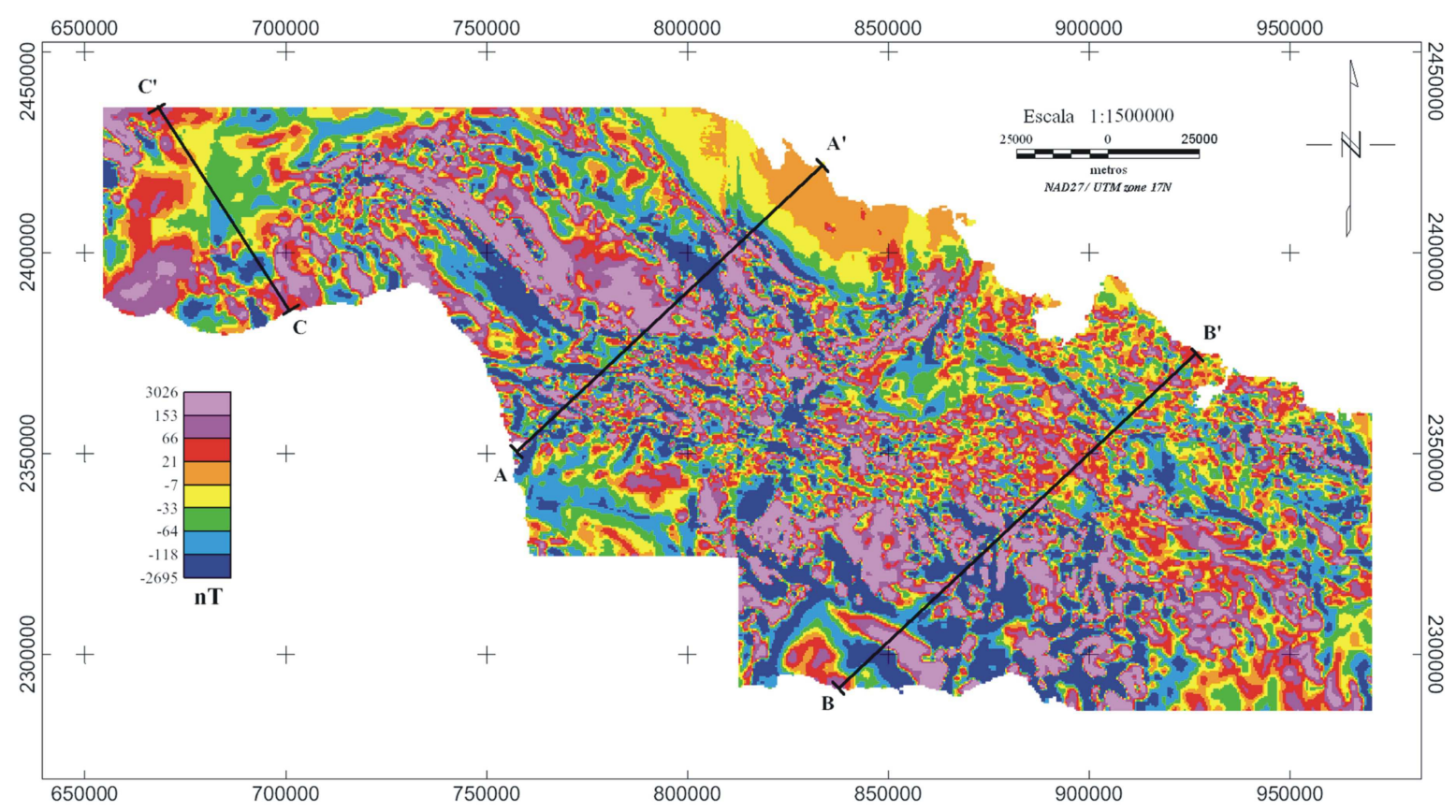

Figura 8 - Mapa residual do campo magnético anômalo até 2.000 m, com perfis de modelagem.

Tabela 1 - Valores médios de densidade e susceptibilidade magnética das unidades geotectônicas que formam o substrato dobrado em Cuba Centro-Oriental (modificado de Pérez et al. 1998).

\begin{tabular}{lcc}
\hline \multicolumn{1}{c}{ Denominação } & $\begin{array}{c}\text { Densidade } \\
\left(\sigma . t / \mathrm{m}^{3}\right)\end{array}$ & $\begin{array}{c}\text { Susceptibilidade } \\
\text { Magnética } \\
\left(\chi \cdot 10^{-5} \mathrm{SI}\right)\end{array}$ \\
\hline Margem continental da Plataforma das Bahamas & 2.80 & 100 \\
Associação ofiolítica & 2.55 & 1500 \\
Arco vulcânico cretácico & 2.67 & 3000 \\
\hline
\end{tabular}


cos realizados em Cuba Centro-Oriental, é o mais consensual na literatura e, portanto, foi o adotado neste estudo. Sumariamente, o modelo de Iturralde-Vinent (1997) advoga a existência de um cinturão orogênico cubano, constituído pelas unidades geotectônicas continental (Plataforma das Bahamas) e oceânica (associação ofiolítica e arco vulcânico cretácico). As unidades oceânicas teriam sido deslocadas para a Plataforma das Bahamas pela subducção e posterior colisão da placa Protocaribenha com a Norte-americana, estando as mesmas cobertas parcialmente por depósitos sedimentares mesozóicos;

2- análise das principais fontes responsáveis pelas anomalias geofísicas e suas respectivas profundidades. Foram levados em consideração, os corpos perturbadores até uma profundidade média de $5000 \mathrm{~m}$;

3- obtenção da resposta dos campos potenciais. Foram confeccionados os mapas residuais do campo gravimétrico (Fig. 7) e do campo magnético anômalo (Fig. 8);

4- modelagem 2-D das fontes supracrustais e intracrustrais (até $5000 \mathrm{~m}$ ). A modelagem baseou-se na proposta de Talwani (1959) e Talwani et al. (1965), onde as anomalias são interativamente observadas e calculadas a partir do re-posicionamento dos polígonos criados, até que a anomalia calculada atinja a melhor correspondência (menor erro) em relação à observada.

Os procedimentos que permitiram a geração dos modelos geológico-geofísicos 2-D foram os seguintes:

1- seleção de perfis regionais, à oeste, centro e leste da área de estudo, compreendendo as principais associações litológicas documentadas em Cuba Centro-Oriental (Fig. 3);

2- definição de parâmetros dos campos físicos, tais como intensidade do campo magnético total, inclinação e declinação do vetor de indução magnética e altura de vôo do aerolevantamento;

3- traçado (no modelo a ser criado) das superfícies correspondentes às profundidades das fontes anômalas previamente selecionadas (até $5000 \mathrm{~m}$ );

4- traçado dos polígonos correspondentes aos corpos causadores das fontes anômalas, definindo os valores de densidade e susceptibilidade magnética aparente, baseados em dados de laboratório (Tabela 1) e mapas petrofísicos (Vega et al. 1994);

5- ajuste da anomalia gravimétrica do modelo à observada;

6- ajuste da anomalia magnética do modelo à observada;

7- confecção do modelo geológico, levando em consideração a análise da geologia superficial presente em cada perfil selecionado.

Esta seqüência de procedimentos foi aplicada aos três perfis selecionados na área de estudo.

DISCUSSÃO DOS RESULTADOS Perfil A-A' O perfilA-A' tem direção SW-NE, azimute $52^{\circ}$ e corta a porção central da área de estudo. Esse perfil secciona as estruturas e rochas de natureza oceânica (arco de ilha-associação ofiolítica) e continental (seqüências do Protocaribe-Plataforma das Bahamas), além de rochas da cobertura Mesozóica (Fig. 3).

O modelo geológico-geofísico gerado com base nessa seção partiu primeiramente da análise da anomalia gravimétrica observada, visando a definição do quadro geológico-estrutural até uma profundidade média de $4000 \mathrm{~m}$ (Fig. 7). O ajuste da anomalia calculada à observada foi obtido com erro de ajuste de $1.3 \mathrm{mGal}$ (Fig. 9).

$\mathrm{O}$ ajuste da anomalia magnética foi realizado estimando-se a profundidade média das fontes anômalas até $5000 \mathrm{~m}$ (Fig. 8), com erro de $64 \mathrm{nT}$ (Fig. 9). Nessa análise, somente foi considerada a magnetização induzida, o que aumenta a complexidade de modela- gem desse campo. Assim, para diminuir as incertezas, ao assumir os valores de susceptibilidade magnética aparente para cada polígono, procurou-se validar um quadro geológico regional.

A interpretação do modelo 2-D para o perfil A-A' permite as seguintes considerações (Tabela 2, Fig. 9):

- de SW para NE, levando-se em conta principalmente o ajuste do modelo gravimétrico e, ocasionalmente, o magnético, foi possível definir a presença de estruturas e unidades relacionadas às espessuras de rochas mesozóicas em contato tectônico com as unidades oceânicas (arco de ilha-associação ofiolítica) e dessas, por sua vez, com as unidades continentais (seqüências do Protocaribe-Plataforma das Bahamas);

- no AVC, o modelo gravimétrico permitiu a diferenciação dos complexos plutônico e vulcano-sedimentar;

- o Complexo Plutônico do AVC, a partir da interpretação gravimagnetométrica realizada nesse trabalho, foi corroborado como uma suíte granítica, caracterizada pela variabilidade lateral e, ocasionalmente vertical, nas propriedades físicas das rochas que a compõem (densidade e susceptibilidade), o que foi geologicamente interpretado como mudanças de fácies na suíte. Essa variação está em sintonia com os trabalhos de Marí et al. (1997) e Pérez \& Sukar (1997), que constataram que esse complexo compreende, fundamentalmente, rochas plutônicas das séries cálcio-alcalina normal (Complexo Tonalito-granodiorítico) e cálcio-alcalino sódica (Complexo Gabro-plagiogranítico);

- o Complexo Vulcano-sedimentar de composição intermediáriaácida pertencente à bacia de retro-arco do AVC é marcado pela queda da intensidade do campo gravimétrico, associado à alta variabilidade do campo magnético;

- o modelo gravi-magnetométrico mostra uma diferenciação a partir dos contrastes de densidade e susceptibilidade no contexto da associação ofiolítica, observando-se uma diminuição da intensidade do campo gravimétrico e alta variabilidade no magnético, o que sugere uma variação de fácies nessa associação (e.g., diferenciação no grau de serpentinização - Iturralde-Vinent 1997);

- o extremo NE do perfil mostra aumento na intensidade do campo gravimétrico e queda e posterior estabilidade do campo magnético, relacionados ao aparecimento de rochas pertencentes à margem continental da Plataforma das Bahamas em contato tectônico com as da associação ofiolítica (Iturralde-Vinent 1997). Essa unidade é constituída pelas seqüências do Protocaribe (calcários estratificados) e pelas seqüências da borda setentrional da Plataforma das Bahamas (calcários e dolomitos).

Perfil B-B' O perfil B-B', de direção SW-NE e azimute $52^{\circ}$, corta a porção leste da área de estudo. A seção modelada inclui rochas da cobertura Mesozóica, do AVC, da associação ofiolítica e da margem continental da Plataforma das Bahamas (Fig. 3). Os perfis gravimétrico e magnético foram ajustados com erros de $1,18 \mathrm{mGal}$ e $65 \mathrm{nT}$, respectivamente (Fig. 10).

A interpretação do modelo 2-D através do perfil B-B' permite as seguintes considerações (Fig. 10 e Tabela 3):

- o modelo gravi-magnetométrico realça a presença de rochas do AVC em contraste com as seqüências mesozóicas e a associação ofiolítica-margem continental das Bahamas;

- a porção central do perfil gravimétrico mostra um marcante contraste de densidade associado ao AVC. Observa-se, na porção SW do perfil, a presença de rochas associadas ao Complexo Vulcano-sedimentar, inferindo-se o aumento da intensidade do campo gravimétrico como devido à variabilidade e alternância do magmatismo efusivo desse complexo (Piñero et al. 1997). Seguin- 
Modelagem 2-D de Dados Gravimétricos e Aeromagnéticos de Cuba Centro-Oriental

Tabela 2 - Resultados da modelagem geológico-geofisica em 2-D do perfil A-A'(azimute $52^{\circ}$ ).

\begin{tabular}{|c|c|c|c|}
\hline Bloco & $\begin{array}{r}\text { Densid } \\
\text { ade } \\
\left(\sigma=\mathrm{t} / \mathrm{m}^{3}\right)\end{array}$ & $\begin{array}{c}\text { Susceptibilidade } \\
\text { Magnética }\left(\chi \cdot 10^{-5} \mathrm{SI}\right)\end{array}$ & Interpretação geológico-geofísica \\
\hline B-1 & 2.38 & 250 & $\begin{array}{l}\text { Sedimentos não consolidados quaternários } \\
\text { (argilosos e arenosos) }\end{array}$ \\
\hline B-2 & 2.68 & 44100 & $\begin{array}{l}\text { Suíte granítica (de composição } \\
\text { intermediária-básica do AVC) }\end{array}$ \\
\hline B-2a & 2.70 & 3000 & $\begin{array}{l}\text { Suíte granítica (de composição } \\
\text { intermediária do AVC) }\end{array}$ \\
\hline$B-3 c$ & 2.55 & 3600 & $\begin{array}{l}\text { Suíte granítica (de composição } \\
\text { intermediária-ácida do AVC) }\end{array}$ \\
\hline B-4 & 2.70 & 4500 & $\begin{array}{l}\text { Suíte granítica (de composição } \\
\text { intermediária-básica do AVC) }\end{array}$ \\
\hline B-5 & 2.60 & 800 & $\begin{array}{l}\text { Complexo efusivo-sedimentar de } \\
\text { composição intermediária-ácida do AVC }\end{array}$ \\
\hline B-6 & 2.52 & 1600 & Associação ofiolítica \\
\hline B-6a & 2.52 & 2200 & Associação ofiolítica \\
\hline B-7 & 2.61 & 200 & Seqüências do Protocaribe da Margem Continental \\
\hline B- 8 & 2.67 & 250 & Plataforma das Bahamas \\
\hline
\end{tabular}

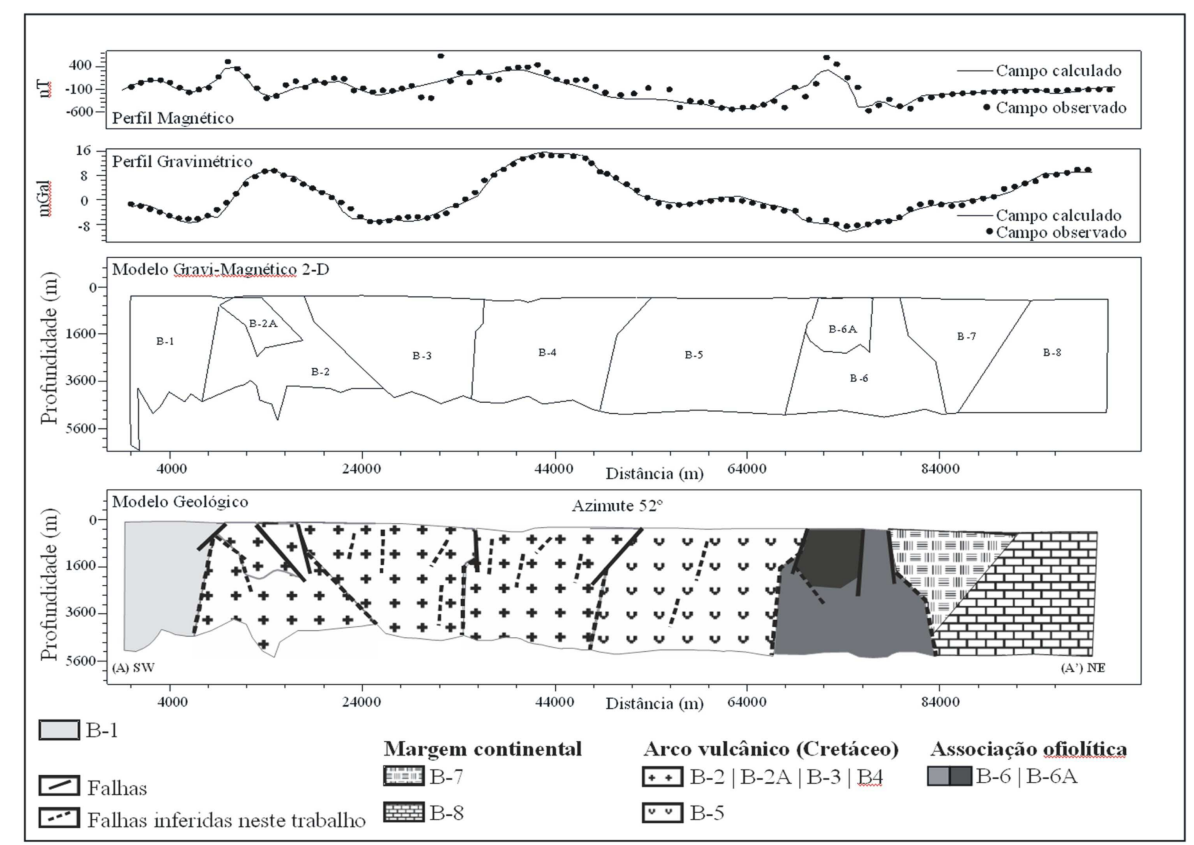

Figura 9 - Modelo geológico-geofísico 2-D através do perfil A-A', Cuba Centro-Oriental. B-1: Sedimentos não consolidados recentes (Q). B-2|B-2A|B-3|B-4: Suíte granítica. B-5: Corpo vulcano-sedimentar de composição intermediária-ácida. B-6|B-6A: Ofiolitos setentrionais. B-7: Sequências do Protocaribe. B-8: Plataforma das Bahamas.

do na direção NE do mesmo perfil, observa-se uma queda e diminuição da intensidade do campo gravimétrico, fato atribuído à presença de um contato tectônico entre rochas pertencentes à suíte granítica de composição intermediária-ácida e às seqüências vulcano-sedimentar do AVC;

- mais a NE no perfil, observa-se uma diminuição da intensidade do campo gravimétrico, a qual pode ser interpretada como devida a sequências espessas de sedimentos (Fig. 10), vinculados à bacia de retro-arco do AVC (Iturralde-Vinent 1997);

- a porção mais extrema a NE do perfil gravimétrico é marcada por um leve incremento e posterior linearidade das intensidades do campo. Esse comportamento é interpretado como função da presença de um corpo tabular constituído pelos ofiolitos setentrionais, entre as estruturas AVC e margem continental das Bahamas. Em superfície, são observadas rochas pertencentes à associação ofiolítica misturadas a sedimentos continentais (Fig. 3);

- o perfil magnético, na mesma secção, apresenta um campo bastante variável. A variabilidade desse campo pode ser função de mudanças faciológicas no Complexo Vulcano-sedimentar (o que, conseqüentemente, provoca mudanças de susceptibilidade 
Rigoberto Lázaro Prieto Cainzos et al.

Tabela 3 - Resultados da modelagem geológico-geofisica em 2-D do perfil B-B'(azimute 52).

\begin{tabular}{|c|c|c|c|}
\hline Bloco & $\begin{array}{l}\text { Densidade } \\
\left(\sigma=t / \mathrm{m}^{3}\right)\end{array}$ & $\begin{array}{c}\text { Susceptibilidade } \\
\text { Magnética }\left(\chi \cdot 10^{-5} \mathrm{SI}\right)\end{array}$ & Interpretação geológico-geofísica \\
\hline B-1 & 2.40 & 500 & $\begin{array}{l}\text { Sedimentos não consolidados recentes } \\
\text { (argilosos e arenosos) }\end{array}$ \\
\hline B-1a & 2.40 & 2000 & $\begin{array}{l}\text { Corpo vulcano-sedimentar (inferido) } \\
\text { de } \\
\text { composição intermediária-ácida do } \\
\text { AVC }\end{array}$ \\
\hline B-2 & 2.60 & 2570 & $\begin{array}{l}\text { Complexo vulcano-sedimentar de } \\
\text { composição intermediária do AVC }\end{array}$ \\
\hline B-3 & 2.65 & 5055 & $\begin{array}{l}\text { Complexo vulcano-sedimentar de } \\
\text { composição intermediária-básica do } \\
\text { AVC }\end{array}$ \\
\hline B-4 & 2.60 & 2300 & $\begin{array}{l}\text { Suíte granítica (de composição } \\
\text { intermediária-ácida do AVC) }\end{array}$ \\
\hline B-5 & 2.30 & 200 & $\begin{array}{l}\text { Sedimentos não consolidados recentes } \\
\text { (argilosos e arenosos) }\end{array}$ \\
\hline$B-6$ & 2.55 & 1555 & Associação ofiolítica \\
\hline B-7 & 2.42 & 500 & Plataforma das Bahamas \\
\hline
\end{tabular}

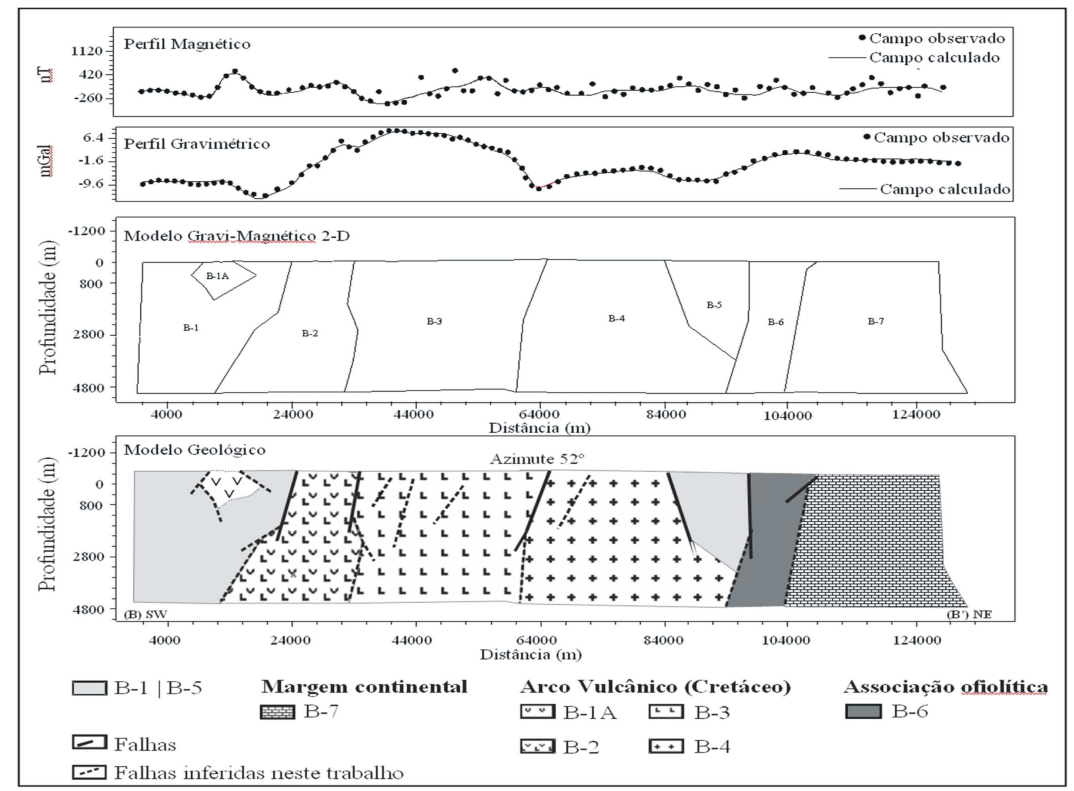

Figura 10 - Modelo geológico-geofisico 2-D através do perfil A-A', Cuba Centro-Oriental. B-1|B-5: Sedimentos não consolidados recentes (Q). B-1A: Corpo vulcano-sedimentar de composição intermediária-ácida (inferido neste trabalho). B-2: Complexo Vulcanosedimentar de composição intermediária. B-3: Complexo Vulcano-sedimentar de composição intermediária- básica. B-4: Suíte granítica. B-6: Ofiolitos setentrionais. B-7: Plataforma das Bahamas.

magnética) e/ou também pode estar associada a zonas de falhas vinculadas ao processo evolutivo do arco.

Perfil C-C' O perfil C-C', de direção SE-NW e azimute $152^{\circ}$, encontra-se situado na porção oeste da área de estudo e corta estruturas do AVC e da chamada "Bacia Central" (Fig. 3). Os perfis gravimétrico e magnético foram ajustados com erros de $0,7 \mathrm{mGal}$ e $35 \mathrm{nT}$, respectivamente.

A interpretação do modelo 2-D através do perfil C-C' é comentada a seguir (Fig. 11 e Tabela 4):
- ao longo do perfil, o campo gravimétrico mostra-se bastante homogêneo, sendo caracterizado por um decréscimo de intensidades, as quais se tornam mais intensas na porção NW. Em superfície, a maior parte da área é coberta por sedimentos terciários e quaternários (Fig. 3). No entanto, a partir do ajuste dos campos físicos na porção inicial do perfil, propõe-se, para o modelo, a presença de um corpo denso e magnético, constituído pela suíte granítica do AVC, de composição intermediária-ácida;

- na porção central do perfil, o campo gravimétrico torna-se gradualmente menos intenso, relacionado à presença de grandes es- 
pessuras de sedimentos recentes, compreendidos na "Bacia Central" (Iturralde-Vinent 1997). No extremo NW do perfil, um leve incremento das intensidades do campo gravimétrico associa-se à presença, em superfície, de rochas pertencentes ao Complexo Vulcano-sedimentar de composição intermediária-básica do AVC;

- como pode ser observado na porção central do perfil, torna-se difícil o ajuste do campo magnético pela alta variabilidade do mesmo. Essa porção da área foi sujeita a fortes movimentos oscilatórios e intenso falhamento, fato que, aparentemente, contribuiu para aumentar a complexidade do campo magnético.

CONCLUSÕES O ajuste dos modelos gravi-magnéticos possibilitou a diferenciação entre as unidades oceânicas (arco vulcânico e associação ofiolítica) e a sua separação da unidade continental da Plataforma das Bahamas.

No modelo, foi possível diferenciar, no AVC, a presença da suíte granítica do Complexo Vulcano-sedimentar. A partir das características e posterior ajuste do campo gravimétrico, foi possível inferir a existência de novas fácies da suíte granítica do AVC, ainda não descritas na literatura de Cuba Centro-Oriental. O ajuste do campo magnético, conjuntamente com o gravimétrico, possibilitou diferenciar o Complexo Vulcano-sedimentar do AVC, de acordo com a composição das rochas constituintes.
O modelo gravi-magnetométrico do perfil A-A' permitiu ainda, separar rochas da associação ofiolítica, sugerindo uma variação de fácies ou variação no grau de serpentinização das rochas dessa associação.

O ajuste do campo gravimétrico da porção mais ao NE do perfil B-B' permitiu definir a estrutura relacionada à bacia de retro-arco do AVC, conforme os modelos propostos por Iturralde-Vinnent et al. $(1997,2000)$.

No modelo do perfil C-C', pelas características dos campos potenciais, foi inferida a presença de um corpo plutônico do AVC, de composição intermediária-básica, na porção SE do perfil. Essa descoberta confirma a hipótese sugerida por Kerr et al. (1999) sobre a continuidade do AVC por toda a extensão de Cuba Centrooriental e sua relação com a evolução de uma bacia de retro-arco junto às rochas ofiolíticas.

Agradecimentos À FAPESP (processo 94/03700-0) pela bolsa de estudo concedida a R.L.P. Cainzos e financiamento da pesquisa, a Dirección Técnica del IGP (Cuba), pela concessão da base de dados geofísicos, e aos revisores do artigo, pelas valiosas sugestões. C.R. de Souza Filho ao CNPq, pela bolsa de Produtividade em Pesquisa (Proc. No. 301.227/94). Aos relatores da RBG pelas sugestões ao manuscrito.

\section{Referências}

Ando J., Harangi S.Z., Szkámy BY., Dosztály L. 1996. Petrología de la asociación ofiolítica de Holguin. In: M.A Iturralde-Vinent..(ed.) Cuban Ophiolites and Volcanic Arc. Project 364: Geological Correlation of Ophiolites and Volcanic Terrenes in the Circum Caribbean Realm, pp.: 154-178.

Capote C., Sánchez R., Lledias P., Santa Cruz-Pacheco M., Escobar E. 1992. Rasgos estructurales de los Arcos Volcánicos Cubanos. In: Geological Conference of Caribbean Pinar Del Rio, 13, Cuba, 123134.

Díaz O.C., Furrazola B.G., Iturralde-Vinent M.A. 1997. Estratigrafia de la zona Remedios. In: B.G. Furrazola, (ed.) Estudios sobre la Geologia de Cuba, CNDIG, Ciudad de la Habana, pp.: 221-242.

Furrazola B.G., Judoley K., Mijailovskay M., Miroliubov Y., Novojatsky I., Nuñez-Jiménez A., Solsona J. 1964. Geologia de Cuba. Consejo Nacional de Universidades, $120 \mathrm{pp}$.

Iturralde-Vinent M.A. 1997. Introducción a la Geología de Cuba. In: B. G. Furrazola (ed.) Estudios sobre la Geología de Cuba, CNDIG, Ciudad de la Habana, pp.: 35-68.

Iturralde-Vinent M.A., Stanek K., Wolf D., Thieke H.U., Müler H. 2000. Geology of the Camaguey Region, Central Cuba Evolution of a Collisional Margin in the Northern Caribbean. In: H. Miller \& F. Hervé (eds.) Zeitschrift für Angewandte Geologie (Geoscientific Cooperation with Latin America-31st International Geological Congress, Rio de Janeiro 2000), pp.: 267-273.

Kerr A.C., Iturralde-Vinent M.A., Saunders A.D., Babbs T.L., Tarney J. 1999. A new plate tectonic model of the Caribbean: Implications from a geochemical reconnaissance of Cuban Mesozoic volcanic rocks. Geol. Soc.Amer. Bulletin, 11:1581-1599.

Khudoley, K. M., Meyerhoff, A. A. 1971. Paleography and geological history of Greater Antilles. Geol. Soc. Amer.Members, 129: 1-199.

Marí T.M. Pérez R.M., Sukar S.K. 1997. Granitoides del Arco Volcánico Cretácico de la Región Central de Cuba (antigua provincia de Camaguey). In: B. G. Furrazola (ed.) Estudios sobre la Geología de Cuba, CNDIG, Ciudad de la Habana, pp.: 387-398.

Meschede M. \& Frisch W. 1998. A plate-tectonic model for the Mesozoic and Early Cenozoic history of the Caribbean plate. Tectonophysics, 296:269-291.

Pérez R.M. \& Sukar S.K. 1997. Granitoides del Arco Volcánico Cretácico de la Región Central de Cuba (antigua provincia de Camaguey). In: B. G. Furrazola (ed.) Estudios sobre la Geología de Cuba, CNDIG, Ciudad de la Habana, 387-398.

Pérez P.E., Pimentel O.H., Pardo E.M. 1998. Interpretación tectónicoestructural de los datos geofísicos en la región Ciego de AvilaCamaguey-Las Tunas, IGP, Relatório técnico-econômico, Ciudad de La Habana.

Pindell J.L., Cande S.C., Pitman III W.C., Rowley D.B., Dewey J.F., Labrecque J., Haxby W. 1988. A plate-kinematic framework for models of Caribbean evolution. Tectonophysics, 155:121-138.

Piñero, P. E., Quintana, M. E., Marí, M. T. 1997. Caracterización Geológica de los depósitos vulcanógeno-sedimentarios de la región de Ciego-Camaguey-Las Tunas. In: B. G. Furrazola (ed.) Estudios sobre la Geología de Cuba, CNDIG, Ciudad de la Habana, 345-356.

Puscharowski, YU. M. (ed.) 1988. Mapa Geológico de la República de Cuba a escala 1:250.000. Academias de Ciencias de Cuba y la Unión Soviética.

Puscharowski, YU. M., Mossakosvky, A. A., Nekrasov, G. E. 1989. Nota explicativa al Mapa Geológico de la República de Cuba a escala 1:250.000. Academias de Ciencias de Cuba y la Unión Soviética, 40 p. 
Tabela 4 - Resultados da modelagem geológico-geofísica em 2-D do perfil C-C'(azimute $152^{\circ}$ ).

\begin{tabular}{|c|c|c|c|}
\hline Bloco & $\begin{array}{l}\text { Densidade } \\
\left(\sigma=t / \mathrm{m}^{3}\right)\end{array}$ & $\begin{array}{c}\text { Susceptibilidade } \\
\text { Magnética }\left(\chi \cdot 10^{-5} \mathrm{SI}\right)\end{array}$ & Interpretação geológico-geofísica \\
\hline B-1 & 2.68 & 3051 & $\begin{array}{l}\text { Suíte granítica inferida (de composição } \\
\text { intermediária-básica doAVC) }\end{array}$ \\
\hline B-2 & 2.55 & 651 & Sedimentos não consolidados recentes \\
\hline B-3 & 2.50 & 455 & Sedimentos neogênicos (argilas calcários) \\
\hline B-4 & 2.65 & 2500 & $\begin{array}{l}\text { Complexo vulcano-sedimentar de composição } \\
\text { intermediária-básica do AVC }\end{array}$ \\
\hline
\end{tabular}
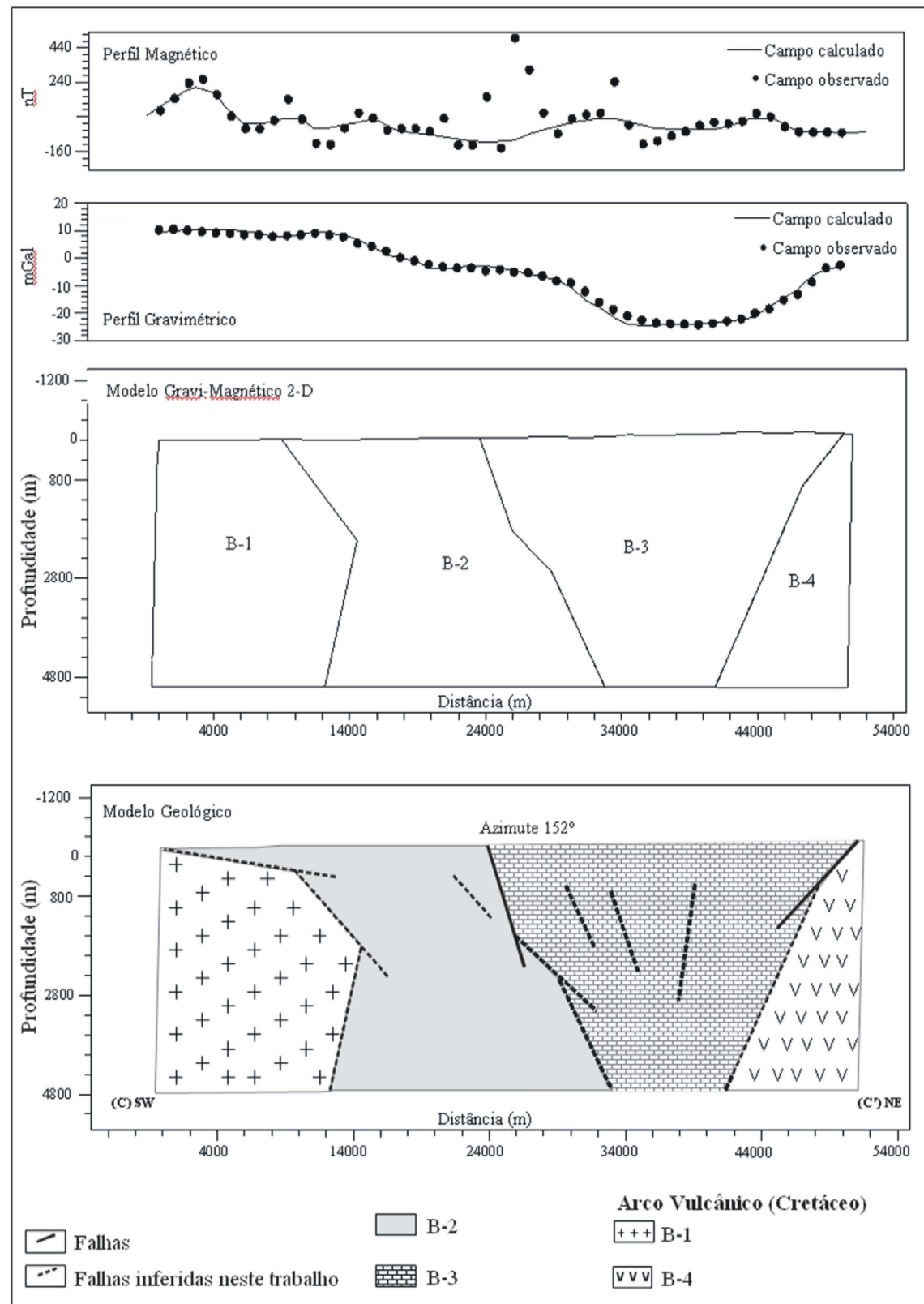

Figura 11 - Modelo geológico-geofísico 2-D através do perfil C-C', Cuba Centro-Oriental. B-1: Suite granítica de composição intermediária-básica (inferida neste trabalho). B-2: Sedimentos não consolidados recentes (Q). B-3: Sedimentos neogênicos (argilas, calcários). B-4. Complexo Vulcano-sedimentar de composição intermediária-básica. 
Ross, M. I., Scotese, C. R. 1988. A hierarchical tectonic model of the Gulf of Mexico and Caribbean region, Tectonophysics, 155: 136-168.

Shein V. S. 1974. Modelo geológico-geofísico de Cuba y su plataforma. In: Jornada Científico-Técnica de Geología, 1, Cuba, Resumen.

Stanek K.P., Cobiella-Reguera J.L., Maresch W.V., Trujillo G.M., Grafe F., Grevel C. 2000. Geological Development of Cuba. In: H. Miller e F. Hervé (eds.) Zeitschrift für Angewandte Geologie (Geoscientific Cooperation with Latin America-31st International Geological Congress, Rio de Janeiro 2000), pp.: 259-265.

Talwani M. 1965. Computation with help of digital computer of magnetic anomalies caused by bodies of arbitrary shape, Geophysics, 30:
$797-817$.

Talwani M., Worzel J. L., Landisman M. 1959. Rapid gravity computations for two-dimensional bodies with application to the Mendocino submarine fracture zone. J.Geophys. Research, 64: 49-59.

Vega M., Pérez C. C., García A. 1994. Mapas petrofísicos de Cuba a escala 1: 1000 000. In: SCG, Congreso Cubano de Geología, 2, Resúmenes Expandidos, p.149.

Manuscrito SR-29

Recebido em 20 de setembro de 2002

Revisão dos autores em 06 de março de 2003

Revisão aceita em 30 de abril de 2003 